\title{
Electrochemical Biosensor for Multiple Methylation-Locus Analysis Based on DNA-AuNPs and Bienzymatic Dual Signal Amplifications
}

\author{
Shasha Su1,2\#, Shu Zhang1,2,3, Jian Huang2,4, Xi Chen1,2, Yan Li1, \\ Lichao Fang1, Jun Deng1, Fei Mo ${ }^{2,3}{ }^{*}$, Junsong Zheng1* \\ ${ }^{1}$ Department of Clinical and Military Laboratory Medicine, College of Medical Laboratory Science, Army Medical University, \\ Shapingba District, Chongqing, China \\ ${ }^{2}$ Department of Basic Clinical Laboratory Medicine, School of Clinical Laboratory Science, Guizhou Medical University, \\ Yunyan District, Guiyang, China \\ ${ }^{3}$ Department of Clinical Laboratory, Affiliated Hospital of Guizhou Medical University, Guiyang, China \\ ${ }^{4}$ Department of Biochemistry, Affiliated Hospital of Guizhou Medical University, Guiyang, China \\ Email: *mofei0312@gmc.edu.cn, ${ }^{*}$ zhengalpha@sina.com
}

How to cite this paper: Su, S.S., Zhang, S., Huang, J., Chen, X., Li, Y., Fang, L.C., Deng, J., Mo, F. and Zheng, J.S. (2020) Electrochemical Biosensor for Multiple Methylation-Locus Analysis Based on DNAAuNPs and Bienzymatic Dual Signal Amplifications. American Journal of Analytical Chemistry, 11, 61-74.

https://doi.org/10.4236/ajac.2020.112005

Received: January 3, 2020

Accepted: February 2, 2020

Published: February 5, 2020

Copyright $\odot 2020$ by author(s) and Scientific Research Publishing Inc. This work is licensed under the Creative Commons Attribution International License (CC BY 4.0).

http://creativecommons.org/licenses/by/4.0/

(c) (i) Open Access

\begin{abstract}
DNA methylation plays a significant role in various biological events, and its precise determination is vital for the prognosis and treatment of cancer. Here, we proposed an ultrasensitive electrochemical biosensor for the quantitative analysis of multiple methylation-locus in DNA sequence via DNA anchoring the gold nanoparticles (DNA-AuNPs) and bienzyme dual signal amplifications. After the target DNA captured by the DNA-AuNPs of the biosensor, the methyl-CpG binding protein $\mathrm{MeCP} 2$ could specifically conjugate to the methylation-loci in the double-stranded DNA. Successively, the glucose oxidase (GOD) and horseradish (HRP) co-labeled antibody captured the His tagged $\mathrm{MeCP}$, which leads to a cascade enzymatic catalysis of the substrates to yield a detectable electrochemical signal. Both the two strategies, including the high content of DNA-AuNPs and the associated catalysis of bienzyme, dramatically enhanced the sensitivity of the biosensor. The response current elevated with the increasing numbers of methylation-locus, thus the multiple methylated DNA was identified by detecting the corresponding current signals. This method could detect the methylated target as low as $0.1 \mathrm{fM}$, and showed a wide linear range from $10-15 \mathrm{M}$ to $10-7 \mathrm{M}$. Besides, the long-term stability and repeatability of the biosensor were also validated. The prepared electrochemical immunosensor exhibits ultrasensitivity through the
\end{abstract}

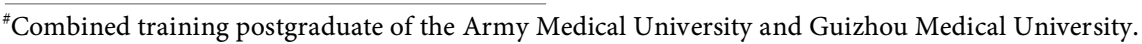


bienzyme labeling process, which can be applied for the detection of DNA methylation with low concentration.

\section{Keywords}

DNA Methylation, Electrochemistry, Biosensor, AuNPs, Bienzyme

\section{Introduction}

DNA methylation has always been the cutting-edge of epigenetic studies, which plays a significant role in cellular development, genomic stability, gene expression and regulation. In eukaryotes, DNA methylation occurs mainly at the carbon-5 position of cytosine residues at $\mathrm{CpG}$ dinucleotides, resulting in the formation of the 5-methylcytosine (5-mC). Normally, a majority of CpG regions in the promoter regions of tumor suppressor genes are unmethylated, once the aberrant methylation occurs, these genes are transcriptionally repressed and inactivated, which is considered as an early warning of tumorigenesis [1]-[8]. Therefore, the determination of DNA methylation can benefit the assessment and classification of tumors. Traditional DNA methylation assays, such as bisulfite sequencing (BS-seq), restriction endonucleases (RE) analysis, high-performance liquid chromatography (HPLC), mass spectrometry (MS), DNA methylation microarrays [9]-[13], generally demand time-consuming, intricate processes or expensive large-scale instruments, which extremely limit their utilization in the analytical and clinical applications. However, electrochemical biosensors offer superior features owing to its simplicity, portability, sensitivity and fast response [14] [15] [16]. Up to now, a number of electrochemical strategies have been established for the detection of DNA methylation. For instance, Geng and Bao utilized the DNA methyltransferases (DNA MTase) to catalyze the formation of 5 -mC coupled with the specific cleavage of methylation-sensitive endonucleases HpaII, which could cleave the unmethylated DNA and lead to the decrease of electrochemical signals of methylene blue $(\mathrm{MB})$ to obtain the methyltransferase detection limit of $0.04 \mathrm{U} / \mathrm{mL}$ with the DNA concentration of $1 \mu \mathrm{M}$ [17]. Using 5-mC antibody, Wang et al. built an electrochemical biosensor which can easily detect the MTase activity and DNA methylation with a detection limit of $0.5 \mu \mathrm{M}$ [18]. Xu et al. also presented a MTase activity detection approach based on the signal amplification of enzyme-modified on the gold nanoparticles to obtain a lower detection limit of $0.17 \mathrm{pM}$ [19]. However, most of reports achieved DNA methylation levels through the enzymatic reactions conducted by DNA MTase without the accurate detection of methylation-locus directly.

As an ideal methylation-specific recognition molecule, the methyl-CpG binding domain (MBD) proteins could be utilized for the quantitative analysis of methylation patterns due to its superior methylation-loci specificity. It is reported that the MBDs include at least the MeCP2, MBD1, MBD2 and MBD4. 
They are capable of binding methylation-locus in double-stranded through their functional MBD domain, indicating that MBDs could be used to serve as the specific recognition unit for the detection of DNA methylation-locus [20] [21].

Immunoassay exhibits high specificity and sensitivity in which the employed immunomolecules were labeled with certain enzyme as molecular labels. Horseradish peroxidase (HRP) is known for its robust capability to catalyze various chemical oxidations involving hydrogen peroxide $\left(\mathrm{H}_{2} \mathrm{O}_{2}\right)$, and it has been extensively employed in electrochemical immunoassays by transforming the redox reaction process into a detectable electrochemical signal [22] [23] [24]. Glucose oxidase (GOD) is also widely used as the signal tracer which specifically catalyzes the oxidation of glucose to gluconic acid, while $\mathrm{O}_{2}$ was reduced to $\mathrm{H}_{2} \mathrm{O}_{2}$ [25] [26]. Theoretically, these two enzymes could be co-labeled on the antibody molecule as amplifying labels. The GOD is catalytically linked to HRP to form bienzymatic cascade scheme, which could produce a further enhanced response signal rather than the one that labeled with mono-enzyme.

The purpose of this study, which involves the methylation-loci recognition unit of $\mathrm{MeCP} 2$ and dual signal amplification from powerful content of DNA anchoring gold nanoparticles (DNA-AuNPs) coupled with bienzyme labeled antibody, is to present an ultrasensitive electrochemical biosensing method for the quantitative analysis of multiple methylation-locus in particular sequence without the need for bisulfite treatment or gene amplification. The electrodeposited AuNPs could enlarge the specific surface area of the electrode, which effectively promote the electron transfer on the electrode and increase the anchoring sites for the self-assembling of the thiolated DNA probes via strong Au-S bond [27] [28] [29]. Thus, the DNA-AuNPs has the potential ability for the enhancement of sensitivity. Also, the bienzyme labeling system could conduct the robust cascade catalysis to produce a further amplified signal and therefore enhanced the sensitivity of the biosensor. As illustrated in Scheme 1, the thiolated singlestranded DNA probe was first self-assembled on the surface of the AuNPsmodified electrode. After the hybridization with the complementary oligonucleotides, the conjugation of the His-tagged MeCP2 was performed. Thereafter, the bienzyme labeled antibody binds to the His-tag of MeCP2 via immunoreactions. In the buffer solution containing glucose and hydroquinone, the GOD could catalyze the glucose substrate to generate $\mathrm{H}_{2} \mathrm{O}_{2}$ by the reduction of ambient oxygen. Then the in situ generated $\mathrm{H}_{2} \mathrm{O}_{2}$ could be rapidly consumed by the nearby HRP. The combination of GOD and HRP formed bienzymatic cascade catalysis to initiate the oxidation of hydroquinone, generating a detectable amplified oxidation current. The current signal was directly related to the amount of methylation-loci, therefore allowing the precise determination of multiple methylation-locus. Impressively, owing to the superior methylation-loci specificity of $\mathrm{MeCP} 2$ and dual signal amplification procedures, this designed method could be a reliable tool for the accurate detection of DNA methylation. 


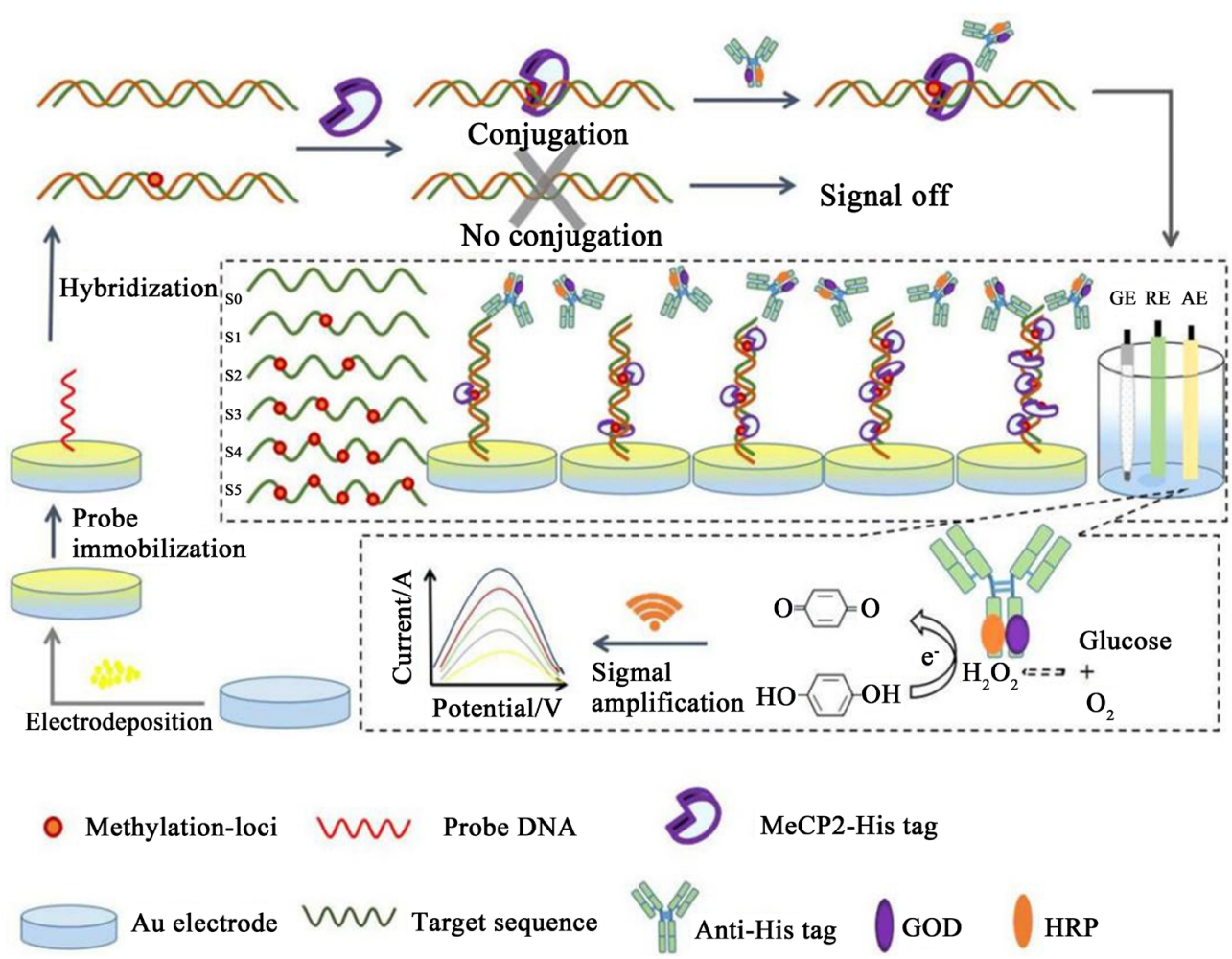

Scheme 1. Schematic illustration of the electrochemical biosensing method for the detection of DNA methylation.

\section{Materials and Methods}

\subsection{Materials}

Hydrogen tetrachloroaurate trihydrate $\left(\mathrm{HAuCl}_{4} \cdot 3 \mathrm{H}_{2} \mathrm{O}\right)$, Tris-EDTA (TE, $\mathrm{pH}$ 7.4) buffer solution and tris (2-carboxyethyl) phosphine (TCEP) were obtained from BBI Life Science Corporation. Bovine serum album (BSA) was purchased from Shanghai Solarbio Bioscience \& Technology Co. Ltd., Recombinant human methyl-CpG-binding protein 2 (MeCP2) was from novoprotein. MeCP2 was produced by mammalian expression system and the target gene encoding Met1-Ser486 was expressed with $6 \times$ His tag at the C-terminus. Anti- $6 \times$ His tag mouse monoclonal antibody, GOD and HRP were obtained from Shanghai Sangon Biotechnology Co. Ltd. The oligonucleotide sequences (Table 1) were synthesized and purified by Shanghai Sangon Biolotechnology Co. Ltd. (China). The oligonucletides were dissolved in TE buffer and stored at $-20^{\circ} \mathrm{C}$.

The buffer solutions used in this work were prepared as follows: Probe immobilization buffer: $1 \times \mathrm{TE}$ buffer (pH 7.4) containing $50 \mathrm{mM} \mathrm{NaCl}$ and $1.0 \mathrm{mM}$ TCEP. DNA hybridization buffer: $1 \times$ TE buffer $(\mathrm{pH}$ 7.4) containing $50 \mathrm{mM}$ $\mathrm{NaCl}$ and $10 \mathrm{mM} \mathrm{MgCl}_{2}$. Phosphate buffered saline (PBS, pH 7.0): $0.01 \mathrm{M}$ $\mathrm{NaH}_{2} \mathrm{PO}_{4}, 0.01 \mathrm{M} \mathrm{Na}_{2} \mathrm{HPO}_{4}$ and $0.01 \mathrm{M} \mathrm{NaCl}$. MeCP2 protein immobilization buffer: $0.1 \mathrm{M}$ phosphate buffered saline and 5\% glycerol. Other reagents were of analytical grade and all the solutions were prepared using ultra-pure water (18.2 $\mathrm{M} \Omega \cdot \mathrm{cm}$ resistivity). 
Table 1. Oligonucleotide sequences used in this work.

\begin{tabular}{|c|c|}
\hline Oligonucleotide & Sequence (5’-3') \\
\hline Probe DNA S & -HS-(CH2)6-GCG CGC TGG GTG GGC GCC GCG GCG CT \\
\hline Target DNA S0 & AGC GCC GCG GCG CCC ACC CAG CGC GC \\
\hline Target DNA S1 & AGC GCC GCG GCG /i5med C/CC ACC CAG CGC GC \\
\hline Target DNA S2 & AG/i5med C/GCC GCG GCG/i5med C/CCA CCC AGC GCG C \\
\hline Target DNA S3 & AG/i5med C/G/i5med C/ CGC GGC G/i5med C/CCA CCC AGC GCG C \\
\hline Target DNA S4 & AG/i5med C/G/i5med C/ CGC GGC G/i5med C/CCA CCC AGC G/i5med C/GC \\
\hline Target DNA S5 & $\begin{array}{l}\text { AG/i5med C/G/i5med C/CG/i5med C/GGC/i5med C/CCA CCC AGC G/i5med } \\
\text { C/GC }\end{array}$ \\
\hline
\end{tabular}

All electrochemical measurements were performed on a CHI660D electrochemical workstation with a conventional three-electrode system: platinum wire as auxiliary electrode, $\mathrm{Ag} / \mathrm{AgCl}$ electrode as reference electrode, and a gold electrode as working electrode. The morphology of nanoparticles and probe immobilization were estimated using scanning electron microscope (SEM, crossbeam 340 zeiss, Germany) and atomic force microscopy (AFM, IPC-208B, Chongqing University), respectively.

\subsection{Methods}

\section{Preparation of bienzyme co-labeled antibody}

The co-labeling of HRP and GOD on the anti-His tag antibody was dealt with a two-stage process. To begin with, the labeling of GOD was performed using the glutaraldehyde cross-link method [30] [31]. The reaction mixture consisted of $1 \mathrm{mg} / \mathrm{mL}$ antibodies and $2 \mathrm{mg}$ GOD in $1.25 \%$ glutaraldehyde solution. Subsequently, the GOD labeled antibodies were coupled to HRP using the sodium periodate procedure through their carbohydrate moieties [32]. The activation of HRP was done in a solution containing $60 \mathrm{mM}$ sodium periodate and $160 \mathrm{mM}$ ethylene glycol. Exactly 1:1 molar rations of antibody to enzyme were taken for the labeling process. Followed by centrifugation and resuspending, the mixture was dialysed in $0.15 \mathrm{M}$ PBS ( $\mathrm{pH} 7.4$ ) and stored at $-20^{\circ} \mathrm{C}$. The obtained products were noted as GOD-HRP/anti-His tag.

\section{Preparation of AuNPs modified electrode}

The $2 \mathrm{~mm}$ diameter gold electrode was polished to a mirror-like surface with $0.05 \mu \mathrm{m}$ alumina slurries, then the polished electrode was ultrasonicated in ethanol and ultrapure water for $5 \mathrm{~min}$ respectively. Next, the electrode was soaked in piranha solution $\left(98 \% \mathrm{H}_{2} \mathrm{SO}_{4}: 30 \% \mathrm{H}_{2} \mathrm{O}_{2}, 3: 1, \mathrm{~V} / \mathrm{V}\right)$ for 15 min. After activation, the bare gold electrode was subjected to electrochemical sweeping in $0.5 \mathrm{M} \mathrm{H}_{2} \mathrm{SO}_{4}$ until the cyclic voltammetry (CV) curve was stable and reduplicative. Followed by thoroughly rinsed with ultrapure water, $3 \mathrm{mM} \mathrm{HAuCl} \cdot 3 \mathrm{H}_{2} \mathrm{O}$ 
solution containing $0.1 \mathrm{M} \mathrm{KNO}_{3}$ was used for the potential deposition at $-0.2 \mathrm{~V}$ for $120 \mathrm{~s}$. Finally, the obtained AuNPs/Au was cleansed again and dried with nitrogen.

\section{Probe immobilization and hybridization}

The probe immobilization was conducted by dropping $10 \mu \mathrm{L}$ of probe immobilization buffer solution (containing $0.1 \mu \mathrm{M}$ thiol-capped probe DNA S) on the surface of AuNPs/Au and incubated for $12 \mathrm{~h}$ at $4^{\circ} \mathrm{C}$ condition to form the Au-S bond. The obtained ssDNA/AuNPs/Au electrode was finally prepared for hybridization. Prior to hybridization, electrode was rinsed thoroughly with PBS and ultrapure water to remove the extra absorbed DNA probe. Then $10 \mu \mathrm{L}$ hybridization buffer (containing $0.1 \mu \mathrm{M}$ target DNA) was dropped on to the probe modified electrode for $60 \mathrm{~min}$ at $37^{\circ} \mathrm{C}$ in a humid atmosphere.

\section{$\mathrm{MeCP} 2$ protein immobilization and immunoreactions}

After hybridization, the electrode was incubated with $0.5 \%$ BSA solution (prepared in $0.1 \mathrm{M}$ PBS) for $30 \mathrm{~min}$. Following that, $10 \mu \mathrm{L}$ of $\mathrm{MeCP} 2$ protein $(200 \mu \mathrm{g} / \mathrm{mL})$ was further dropped and incubated for $60 \mathrm{~min}$ at $37^{\circ} \mathrm{C}$. Washed with PBS repeatedly, the electrode was incubated with $10 \mu \mathrm{L}$ GOD-HRP/anti-His $\operatorname{tag}(10 \mu \mathrm{g} / \mathrm{mL})$ at $37^{\circ} \mathrm{C}$. Afterward, the electrode was rinsed again with PBS.

\section{Electrochemical characterization and determination}

Cyclic voltammetry (CV) and electrochemical impedance spectroscopy (EIS) were used to characterize the assembled process of electrode in $3 \mathrm{mM}\left[\mathrm{Fe}(\mathrm{CN})_{6}\right]^{3-} /^{4-}$ (1:1) solution containing $0.1 \mathrm{M} \mathrm{KCl}$ at a scan rate of $50 \mathrm{mV} / \mathrm{s}$. To detect the electrochemical signals, differential pulse voltammetry (DPV) was carried out in 10 $\mathrm{mL}$ of $0.1 \mathrm{M}$ PBS containing $0.5 \mathrm{mM}$ glucose and $0.25 \mathrm{mM}$ hydroquinone with the scan potential range from $-0.1 \mathrm{~V}$ to $0.6 \mathrm{~V}$. Other parameters were as follows: pulse width, $0.05 \mathrm{~s}$; pulse amplitude, $50 \mathrm{mV}$; sampling width, $0.0167 \mathrm{~s}$; pulse period, $0.5 \mathrm{~s}$; quite time, $2 \mathrm{~s}$.

\section{Results and Discussion}

\section{UV-vis spectrophotometer analysis}

The coupling products were identified by ultraviolet and visible (UV-vis) scanning at a range of $200-800 \mathrm{~nm}$. As can be seen in Figure 1, two absorption peaks are observed at the wavelength of $403 \mathrm{~nm}$ and $275 \mathrm{~nm}$, representing the UV absorption spectra of HRP/antibody and GOD/antibody, respectively [32] [33] [34]. Due to the combined modification of antibody with these two enzymes, there was shift of absorption peak at $403 \mathrm{~nm}$ and $275 \mathrm{~nm}$, which confirmed an efficient bienzyme modification to the antibody.

\section{Morphological characterization of AuNPs/Au and ssDNA/AuNPs/Au}

According to the SEM image (Figure 2(a)), it can be observed that the AuNPs are spherical and in good distribution with an average particle size of $32 \mathrm{~nm}$, so the superficial area of the electrode was enlarged. The AuNPs/Au and ssDNA/AuNPs/Au were compared by AFM. Figure 2(b) and Figure 2(c) show the AFM images of AuNPs monolayer and the immobilization of the captured 


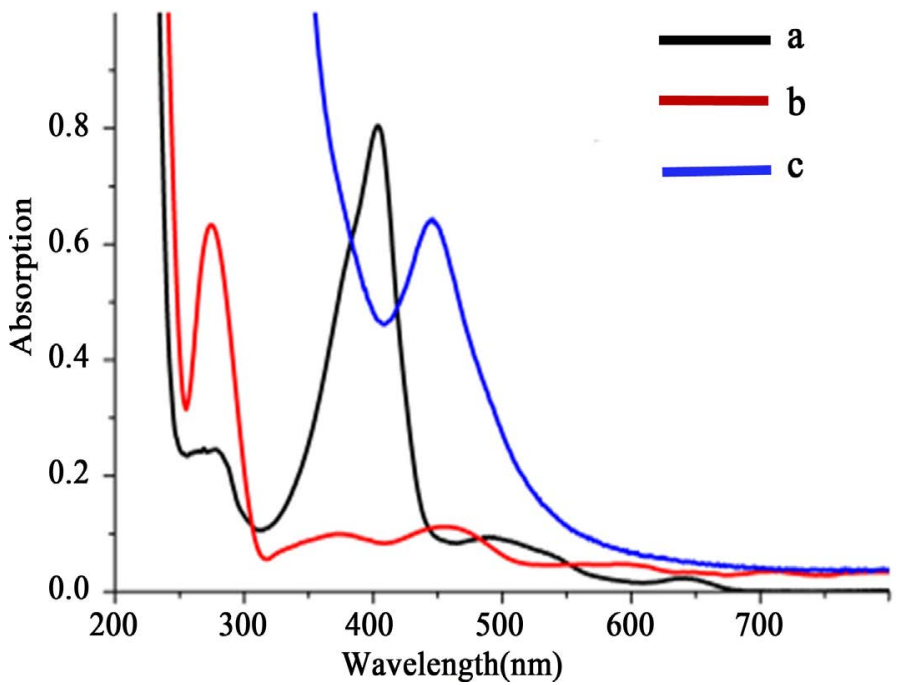

Figure 1. Image of UV absorption spectra of HRP/anti-His tag (a), GOD/anti-His tag (b) and GOD-HRP/anti-His tag (c).
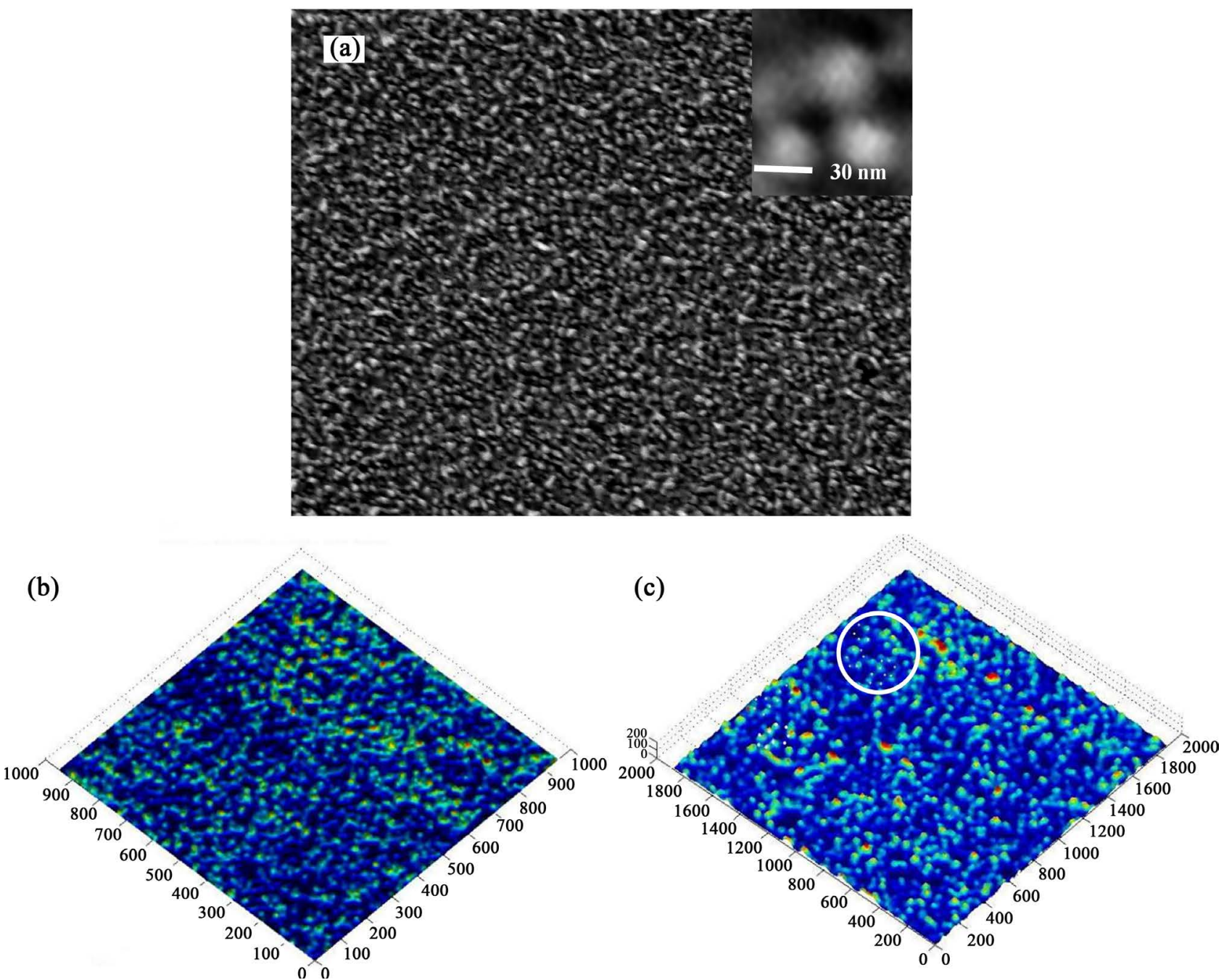

Figure 2. (a) SEM image of AuNPs/Au. (b) AFM image of AuNPs/Au. (c) AFM image of ssDNA/AuNPs/Au. 
probe. The AFM parameters have been evaluated for $1000 \times 1000 \mathrm{~nm}$ and 2000 $\times 2000 \mathrm{~nm}$ surface area. It is significant that there are morphological differences between both the films. The view of AuNPs/Au (Figure 2(b)) shows uniformly deposited homogeneously dispersed AuNPs on electrode, which showed consistent particle sizes with those of SEM. After the modification of ssDNA probe, it can be observed the high brightness white dots which were marked by a white circle and the surface morphology became rougher (Figure 2(c)), giving the increased height of ssDNA anchoring on the surface of the AuNPs/Au films.

\section{Electrochemical characterization of the biosensor}

EIS was employed to characterize the electrode fabrication process. As depicted in Figure 3(a), curve a shows a small semicircle, which indicates a very low impedance of the bare gold electrode. When the bare gold electrode was modified with AuNPs, a straight line was observed (curve b), suggesting that the AuNPs could effectively promote the electron transfer of $\left[\mathrm{Fe}(\mathrm{CN})_{6}\right]^{3-/ 4-}$. However, since the negatively charged phosphate backbone of DNA could repulse the diffusion of $\left[\mathrm{Fe}(\mathrm{CN})_{6}\right]^{3-/ 4-}$ on the electrode surface, the impedance value increased after the probe DNA was immobilized on the AuNPs/Au surface (curve c), and a further increase was observed after the hybridization process (curve d). After the MeCP2 protein conjugated to the DNA methylation-loci, the assembled protein could also block the transfer on the electrode, so the impedance value continued to elevate (curve e).

We also employed CV to monitor each step of the fabricating process (Figure $3(b))$. The CV curve showed a pair of distinct redox peaks, indicating that the electron transfer of $\left[\mathrm{Fe}(\mathrm{CN})_{6}\right]^{3-/ 4-}$ on the electrode surface. The bare gold showed a well-defined redox peak with the current of $0.625 \mu \mathrm{A}$ (curve a). The separation of peak-to-peak $(\Delta \mathrm{Ep})$ was $0.077 \mathrm{~V}$. After the AuNPs were electrodeposited on the bare gold surface, the redox peak current increased with the decreased $\Delta \mathrm{Ep}$ (curve b). This phenomenon was caused by the excellent conductivity of AuNPs, which increased the electrode effective surface and improved the electron transfer
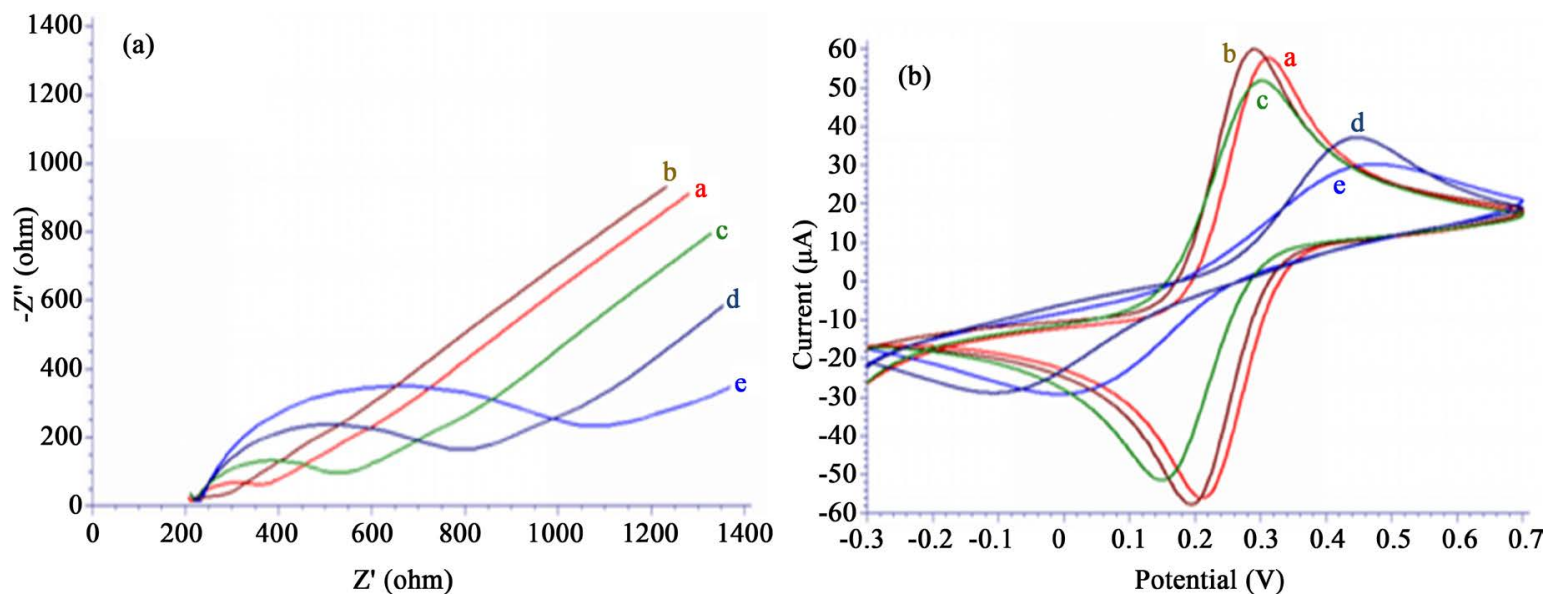

Figure 3. Characterization of EIS (a) and CV (b) obtained for the fabricated process. a. Bare gold electrode; b. AuNPs modified gold electrode; c. Probes self-assembly; d. Hybridization with target DNA; e. MeCP2 conjugation. 
rate. However, the redox peak current of $\left[\mathrm{Fe}(\mathrm{CN})_{6}\right]^{3-14-}$ decreased when the DNA probe was immobilized through the Au-S bond due to the electrostatic repulsion force between the negatively charged $\left[\mathrm{Fe}(\mathrm{CN})_{6}\right]^{3-/ 4-}$ and the negatively charged DNA (curve c), thereby decreasing the redox peak current and enlarging the distance between two peaks. In short, the electrode surface had been successfully modified with this probe. Then, the redox peak current further decreased after the probe DNA hybridized with target sequences (curve d) due to the number of negative charges on the gold electrode surface continued to rise, so the electron transfer ability of $\left[\mathrm{Fe}(\mathrm{CN})_{6}\right]^{3-/ 4-}$ was further attenuated, which then reduced the redox peak current. Subsequently, when MeCP2 protein conjugated with the methylated DNA, the redox peak current decreased obviously (curve e). The current decrease can be attributed to the steric hindrance caused by the large volume of $\mathrm{MeCP} 2$ protein, which blocked the diffusion of $\left[\mathrm{Fe}(\mathrm{CN})_{6}\right]^{3-14-}$ towards electrode surface and decreased the electron transfer rate. Collectively, each modification step of the electrochemical biosensor was successful. This was in accordance with the results of other studies [18] [19]. The CV results correspond to the EIS for each step of the electrode modification process, which confirmed the successful modification steps on the working electrode.

\section{Optimization of experimental conditions}

Optimized experimental parameters including the hybridization time, MeCP2 and substrates concentration are vital to the performance of the proposed method. All the parameters mentioned above were validated and we selected the optimal experimental conditions according to the results. Parameters of $60 \mathrm{~min}$ (hybridization time), $200 \mu \mathrm{g} / \mathrm{mL}$ (MeCP2 concentration), $0.5 \mathrm{mM}$ (glucose substrate concentration) and $0.25 \mathrm{mM}$ (hydroquinone substrate concentration) were used in the study.

\section{Analysis of DNA methylation patterns in particular sequence}

DNA S0-S5 containing known amount of methylation-locus were hybridized with probe DNA S, and then the MeCP2 and antibody conjugations were validated. Figure 4(a) shows the DPV results derived from the target sequence with various methylation-locus and the peak current increased with the growing numbers of methylation-locus. Due to the quantitative conjugation of the $\mathrm{MeCP} 2$ to the methylation-loci in the target sequence, the subsequent specific recognizing by the bienzyme modified antibodies, and the current signal generations under the catalysis of the enzymes of GOD and HRP, the current signal were highly related to the levels of the DNA methylation-locus and the linear relationship was exhibited in Figure 4(b). On the contrary, a weak background current for the unmethylated sequence is also observed (Figure 4(a), curve a) for there was only a small amount of nonspecifically absorbed proteins or antibodies on the electrode. The results demonstrated that the proposed strategy can be applied to the selective identification of DNA methylation patterns.

Characterization of the bienzyme signal amplification

In order to prove the electrocatalytic effect of the bienzyme system, we conducted 
a comparison test by using three kinds of labeled antibodies with GOD/anti-His tag, HRP/anti-His tag and GOD-HRP/anti-His tag, respectively. The tests were investigated through the DPV signal to $0.1 \mu \mathrm{M}$ target sequence with one methyaltion-loci. As shown in Figure 5, the bienzyme system shows a strong oxidation current of about $6.37 \mu \mathrm{A}$ (curve c), increased to 3.2 fold than the monoenzyme HRP (curve b). In contrast, an extremely low current signal was obtained when the anti-His tag antibody was merely modified with GOD (curve a), indicating that the oxidation of hydroquinone by $\mathrm{H}_{2} \mathrm{O}_{2}$ was inefficient without HRP. These results indicate that the bienzyme co-labeling procedure was successful and could considerably enhance the sensitivity of the biosensor.

\section{Sensitivity, repeatability and stability of the biosensor}

We evaluated the DPV responses of different DNA concentrations with only one methylation-loci. Figure 6(a) indicates that the peak currents are increasing along with increased concentration of target DNA across the range of $10^{-15} \mathrm{M}$ to $10^{-7} \mathrm{M}$, and the linear relationship between DPV peak current and the logarithm
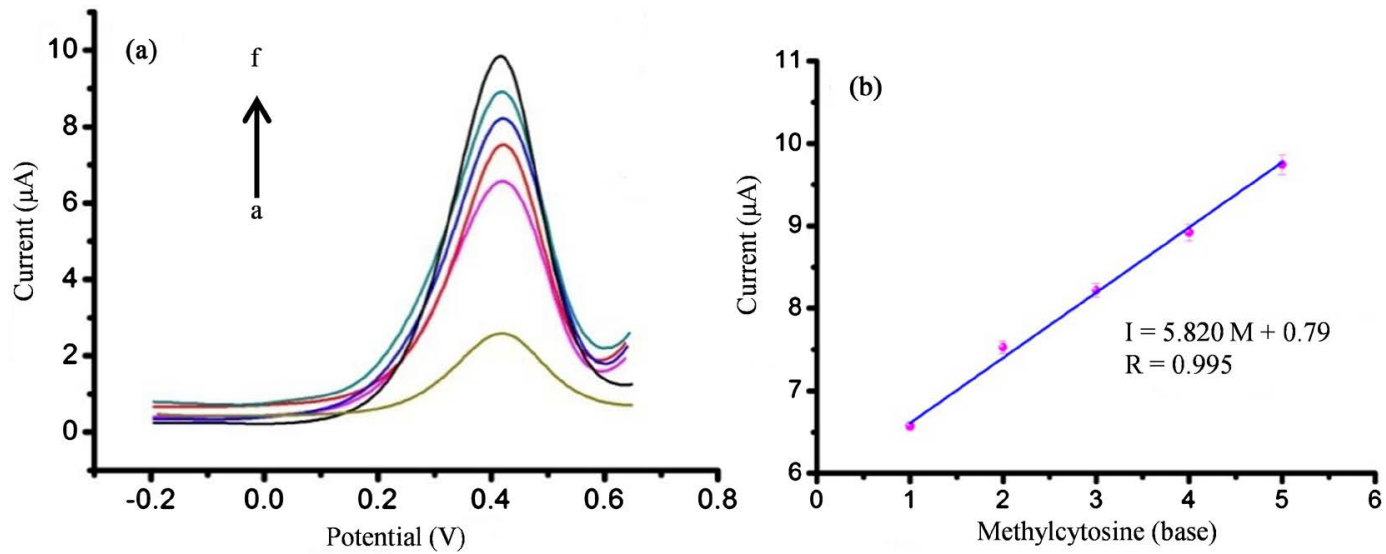

Figure 4. (a) DPV analysis of methylation patterns S0-S5 (a-f), DNA S0 was unmethylated. DNA S1-S5 have 1, 2, 3, 4, 5 methylation locus in each sequence. (b) The linear relationship between peak current and the amount of methylation-locus from 1 to 5 .

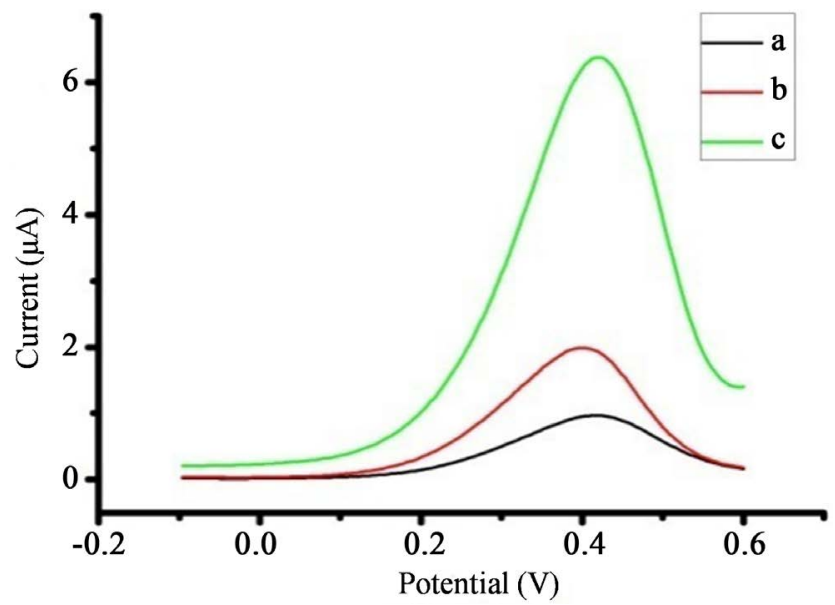

Figure 5. DPV responses obtained for the different enzyme-labeled antibodies. (a) GOD labeled anti-His tag. (b) HRP labeled anti-His tag. (c) GOD and HRP co-labeled anti-His tag. 
of the DNA concentration can be expressed as $I(\mu \mathrm{A})=0.548 \log \mathrm{C}(\mathrm{M})+10.306$ with a correlation coefficient (R) of 0.989 (Figure 6(a)). Comparing to the previous assays (Table 2), our method is proven to be a sensitive tool for the detection of DNA methyaltion.

The repeatability of the proposed method was conducted by detecting the target DNA with one methylation-loci for five repeat measurements. The relative standard deviation (RSD) value was $4.6 \%$, which is lower than previously reported studies [35] [36] [37]. The results illustrate an ideal repeatability of the proposed method.

The long-term stability of the biosensor was also investigated. We stored the prepared biosensors in $\mathrm{pH} 7.4 \mathrm{PBS}$ at $4^{\circ} \mathrm{C}$ and detected every seven days. The current responses were stable, and finally retained $93.7 \%$ of its initial redox current after storage of 28 days.

\section{Conclusion}

In this work, we successfully fabricated an enhanced electrochemical biosensor for the quantitative analysis of multiple methylation-locus in particular sequence with $\mathrm{MeCP} 2$ as the specific recognition unit. A lower detection limit of $0.1 \mathrm{fM}$ was achieved owing to the dual signal amplification of the AuNPs and bienzymatic
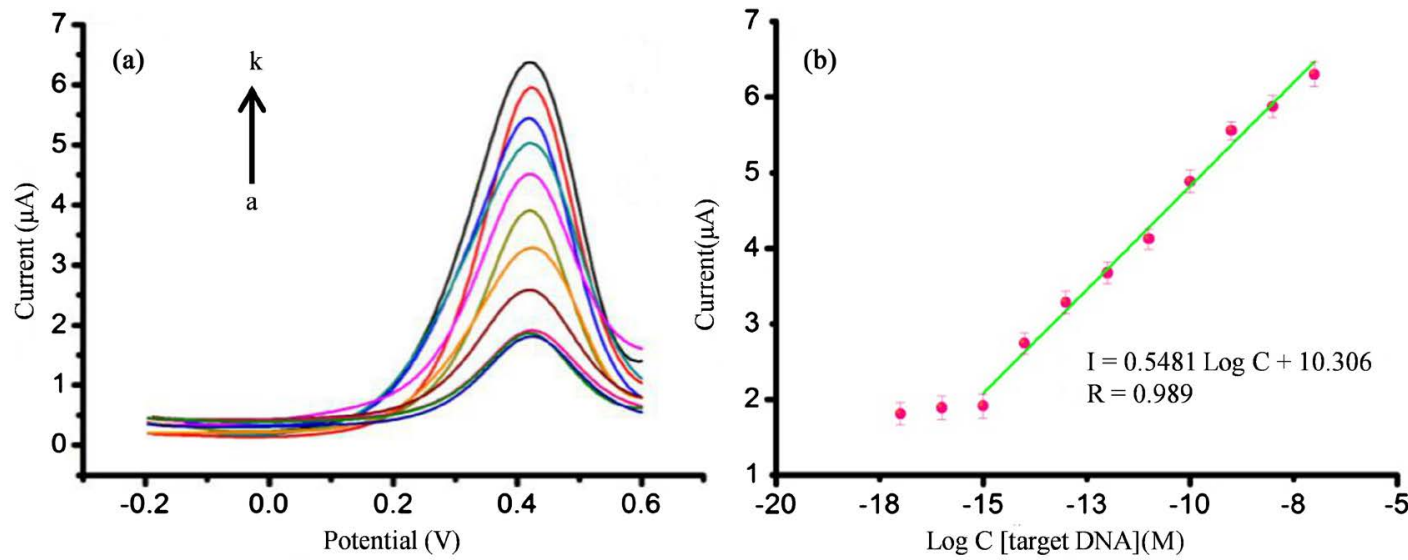

Figure 6. (a) DPV responses of different DNA concentration (a - k: $10-17 \mathrm{M}, 10-16 \mathrm{M}, 10-15 \mathrm{M}, 10-14$ M, 10 - 13 M, $10-12$ M, $10-11$ M, $10-10$ M, 10 - 9 M, 10 - 8 M, 10 - 7 M, respectively). (b) The linear relationship of peak current versus the logarithm of DNA concentration.

Table 2. Comparison with previous reports.

\begin{tabular}{cccc}
\hline Approaches & Linear range $(\mathrm{M})$ & Detection limit $(\mathrm{M})$ & Reference \\
\hline Electrochemistry & $5.0 \times 10^{-11}-9.6 \times 10^{-8}$ & $1.8 \times 10^{-11}$ & Wang et al. 2012 \\
Electrochemistry & $0.5 \times 10^{-9}-10 \times 10^{-9}$ & $0.5 \times 10^{-9}$ & Yanagisawa et al. 2015 \\
Immunoassay & $0.5 \times 10^{-8}-0.5 \times 10^{-7}$ & $2.6 \times 10^{-9}$ & Wu et al. 2018 \\
Colorimetric & $1 \times 10^{-13}-1 \times 10^{-8}$ & $9.3 \times 10^{-14}$ & Gao et al. 2017 \\
Fluorescence & $3.2 \times 10^{-15}-8.0 \times 10^{-13}$ & $3.1 \times 10^{-16}$ & Dadmehr et al. 2014 \\
This work & $1 \times 10^{-15}-1 \times 10^{-7}$ & $1 \times 10^{-17}$ & $/$ \\
\hline
\end{tabular}


cascade catalysis. The repeatability and stability were also validated. Comparing with other biosensing approaches based on conventional bisulfate conversion or methylation restriction enzyme cleavage, our presented method is much easier, cheaper and more time-saving, indicating that our method possesses great prospect for the clinic application in the early diagnosis of cancer and other methylation-related diseases.

\section{Acknowledgements}

This work was supported by the National Natural Science Foundation of China (No. 81572078, No. 81401722 and No. 81873982), the Projects of Basic Research and Frontier Exploration in Chongqing (No. cstc2019jcyj-zdxm0037), and the army Innovation Research Project (No. LJ20182B060005).

\section{Conflicts of Interest}

The authors declare no conflicts of interest regarding the publication of this paper.

\section{References}

[1] Suzuki, M.M. and Bird, A. (2008) DNA Methylation Landscapes: Provocative Insights from Epigenomics. Nature Reviews Genetics, 9, 465-476.

https://doi.org/10.1038/nrg2341

[2] Dirk, S. (2015) Function and Information Content of DNA Methylation. Nature, 517, 321-326. https://doi.org/10.1038/nature14192

[3] Smith, Z.D. and Meissner, A. (2013) DNA Methylation: Roles in Mammalian Development. Nature Reviews Genetics, 14, 204-220. https://doi.org/10.1038/nrg3354

[4] Ehrlich, M., Gama-Sosa, M.A., Huang, L.H., et al. (1982) Amount and Distribution of 5-Methylcytosine in Human DNA from Different Types of Tissues of Cells. Nucleic Acids Research, 10, 2709-2721. https://doi.org/10.1093/nar/10.8.2709

[5] Kader, F. and Ghai, M. (2015) DNA Methylation and Application in Forensic Sciences. Forensic Science International, 249, 255-265.

https://doi.org/10.1016/j.forsciint.2015.01.037

[6] Chen, M., Voeller, D., Marquez, V.E., et al. (2010) Enhanced Growth Inhibition by Combined DNA Methylation/HDAC Inhibitors in Lung Tumor Cells with Silenced CDKN2A. International Journal of Oncology, 37, 963-971. https://doi.org/10.3892/ijo_00000747

[7] Scesnaite, A., Jarmalaite, S., Mutanen, P., et al. (2012) Similar DNA Methylation Pattern in Lung Tumours from Smokers and Never-Smokers with Second-Hand Tobacco Smoke Exposure. Mutagenesis, 27, 423-429. https://doi.org/10.1093/mutage/ger092

[8] Baek, S.J., Yang, S., Kang, T.W., et al. (2013) MENT: Methylation and Expression Database of Normal and Tumor Tissues. Gene, 518, 194-200. https://doi.org/10.1016/j.gene.2012.11.032

[9] Von Kanel, T., Gerber, D., Schaller, A., et al. (2010) Quantitative 1-Step DNA Methylation Analysis with Native Genomic DNA as Template. Clinical Chemistry, 56, 1098-1106. https://doi.org/10.1373/clinchem.2009.142828

[10] Bakshi, A., Ekram, M.B, and Kim, J. (2015) Locus-Specific DNA Methylation Anal- 
ysis of Retrotransposons in ES, Somatic and Cancer Cells Using High-Throughput Targeted Repeat Element Bisulfite Sequencing. Genomics Data, 3, 87-89. https://doi.org/10.1016/j.gdata.2014.11.013

[11] Head, J.A., Mittal, K. and Basu, N. (2015) Application of the LUminometric Methylation Assay to Ecological Species: Tissue Quality Requirements and a Survey of DNA Methylation Levels in Animals. Molecular Ecology Resources, 14, 943-952. https://doi.org/10.1111/1755-0998.12244

[12] Huang, W., Qi, C.B., Lv, S.W., et al. (2015) Correction to Determination of DNA and RNA Methylation in Circulating Tumor Cells by Mass Spectrometry. Analytical Chemistry, 88, 1378-1384. https://doi.org/10.1021/acs.analchem.5b03962

[13] Bibikova, M., Barnes, B., Tsan, C., et al. (2011) High Density DNA Methylation Array with Single CpG Site Resolution. Genomics, 98, 288-295.

https://doi.org/10.1016/j.ygeno.2011.07.007

[14] Su, J., He, X., Wang, Y., Wang, K., Chen, Z.F. and Yan, G. (2012) A Sensitive Signal-on Assay for MTase Activity Based on Methylation-Responsive Hairpin-Capture DNA Probe. Biosensors and Bioelectronics, 36, 123-128.

https://doi.org/10.1016/j.bios.2012.04.012

[15] Shen, Q., Han, L., Fan, G., et al. (2015) Highly Sensitive Photoelectrochemical Assay for DNA Methyltransferase Activity and Inhibitor Screening by Exciton Energy Transfer Coupled with Enzyme Cleavage Biosensing Strategy. Biosensors and Bioelectronics, 64, 449-455. https://doi.org/10.1016/j.bios.2014.09.044

[16] Peng, X., Hu, T., Bao, T., Zhao, L., et al. (2017) A Label-Free Electrochemical Biosensor for Methytransferase Activity Detection and Inhibitor Screening Based on Graphene Quantum Dot and Enzyme-Catalyzed Reaction. Journal of Electroanalytical Chemistry, 799, 327-332. https://doi.org/10.1016/j.jelechem.2017.06.030

[17] Bao, J., Geng, X., Hou, C., et al. (2018) A Simple and Universal Electrochemical Assay for Sensitive Detection of DNA Methylation, Methyltransferase Activity and Screening of Inhibitors. Journal of Electroanalytical Chemistry, 814, 144-152. https://doi.org/10.1016/j.jelechem.2018.02.060

[18] Wang, M., Xu, Z., Chen, L., Yin, H. and Ai, S. (2012) Electrochemical Immunosensing Platform for DNA Methyltransferase Activity Analysis and Inhibitor Screening. Analytical Chemistry, 84, 9072-9078. https://doi.org/10.1021/ac301620m

[19] Xu, Z., Yin, H., Huo, L., Zhou, Y. and Ai, S. (2014) Electrochemical Immunosensor for DNA Methyltransferase Activity Assay Based on Methyl CpG-Binding Protein and Dual Gold Nanoparticle Conjugate-Based Signal Amplification. Sensors and Actuators B: Chemical, 192, 143-149. https://doi.org/10.1016/j.snb.2013.10.099

[20] Yu, Y., Blair, S., Gillespie, D., et al. (2010) Direct DNA Methylation Profiling Using Methyl Binding Domain Proteins. Analytical Chemistry, 82, 5012-5019.

https://doi.org/10.1021/ac1010316

[21] Du, Q., Lu, P.L., Stirzaker, C. and Clark, S.J. (2015) Methyl-CpG-Binding Domain Proteins: Readers of the Epigenome. Epigenomics, 7, 1051-1073.

https://doi.org/10.2217/epi.15.39

[22] Zhuo, Y., Yi, W.J., Lian, W.B., et al. (2011) Ultrasensitive Electrochemical Strategy for NT-proBNP Detection with Gold Nanochains and Horseradish Peroxidase Complex Amplification. Biosensors and Bioelectronics, 26, 2188-2193. https://doi.org/10.1016/j.bios.2010.09.033

[23] Lu, D.Q., Xu, Q.D., Pang, G.C. and Lu, F. (2018) A Novel Electrochemical Immunosensor Based on Au Nanoparticles and Horseradish Peroxidase Signal Amplification for Ultrasensitive Detection of $\alpha$-Fetoprotein. Biomedical Microdevices, 20, 
46-58. https://doi.org/10.1007/s10544-018-0291-7

[24] Pelossof, G., Tel-Vered, R., Elbaz, J. and Willner, I. (2010) Amplified Biosensing Using the Horseradish Peroxidase-Mimicking DNAzyme as an Electrocatalyst. Analytical Chemistry, 82, 4396-4402. https://doi.org/10.1021/ac100095u

[25] Bankar, S.B., Bule, M.V., Singhal, R.S. and Ananthanarayan, L. (2009) Glucose Oxidase-An Overview. Biotechnology Advances, 27, 489-501.

https://doi.org/10.1016/j.biotechadv.2009.04.003

[26] Feng, Q., Liu, K., Fu, J., et al. (2012) Direct Electrochemistry of Hemoglobin Based on Nano-Composite Film of Gold Nanopaticles and Poly (Diallyldimethylammonium Chloride) Functionalized Graphene. Electrochimica Acta, 60, 304-308. https://doi.org/10.1016/j.electacta.2011.11.048

[27] Baron, R., Willner, B. and Willner, I. (2007) Biomolecule-Nanoparticle Hybrids as Functional Units for Nanobiotechnology. Chemical Communications, 38, 323-332. https://doi.org/10.1039/B610721B

[28] Cao, Y., Yuan, R., Chai, Y., et al. (2012) Ultrasensitive Luminol Electrochemiluminescence for Protein Detection Based on in Situ Generated Hydrogen Peroxide as Coreactant with Glucose Oxidase Anchored AuNPs@MWCNTs labeling. Biosensors and Bioelectronics, 31, 305-309. https://doi.org/10.1016/j.bios.2011.10.036

[29] Jing, X., Cao, X., Wang, L., et al. (2014) DNA-AuNPs Based Signal Amplification for Highly Sensitive Detection of DNA Methylation, Methyltransferase Activity and Inhibitor Screening. Biosensors and Bioelectronics, 58, 40-47. https://doi.org/10.1016/j.bios.2014.02.035

[30] Avrameas, S. (1969) Coupling of Enzymes to Proteins with Glutaraldehyde: Use of the Conjugates for the Detection of Antigens and Antibodies. Immunochemistry, 6, 49-52. https://doi.org/10.1016/0019-2791(69)90177-3

[31] Avrameas, S. and Ternynck, T. (1969) The Cross-Linking of Proteins with Glutaraldehyde and Its Use for the Preparation of Immunoadsorbents. Immunochemistry, 6, 53-66. https://doi.org/10.1016/0019-2791(69)90178-5

[32] Regidi, S., Ravindran, S., Vijayan, A.L., et al. (2018) Effect of Lyophilization on HRP-Antibody Conjugation: An Enhanced Antibody Labeling Technology. BMC Research Notes, 11, 596-601. https://doi.org/10.1186/s13104-018-3688-8

[33] Yang, H., Gong, C.C., Miao, L.F. and Xu, F. (2017) A Glucose Biosensor Based on Horseradish Peroxidase and Gkusoce Oxidase Co-Entrapped in Carbon Nanotubes Modified Electrode. International Journal of Electrochemical Science, 12, 4958-4969. https://doi.org/10.20964/2017.06.05

[34] Zhang, Q., Wu, S.Y. and Zhang, L. (2011) Fabrication of Polymeric Ionic Liquid/Graphene Nanocomposite for Glucose Oxidase Immobilization and Direct Electrochemistry. Biosenors and Bioelectronics, 26, 2632-2637. https://doi.org/10.1016/j.bios.2010.11.024

[35] Yin, H., Zhou, Y., Xu, Z., Wang, M. and Ai, S. (2013) Ultrasensitive Electrochemical Immunoassay for DNA Methyltransferase Activity and Inhibitor Screening Based on Methyl Binding Domain Protein of MeCP2 and Enzymatic Signal Amplification. Biosensors and Bioelectronics, 49, 39-45. https://doi.org/10.1016/j.bios.2013.04.040

[36] Liu, P., Liu, M., Yin, H., Zhou, Y. and Ai, S.Y. (2015) Electrochemical Biosensor for DNA Methyltransferase Detection Based on DpnI Digestion Triggering the Formation of G-Quadruplex DNAzymes. Sensors and Actuators B: Chemical, 220, 101-106. https://doi.org/10.1016/j.snb.2015.05.058

[37] Koo, K.M., Wee, E.J.H., Rauf, S., et al. (2014) Microdevices for Detecting Locus-Specific DNA Methylation at CpG Resolution. Biosensors and Bioelectronics, 56, 278-285. https://doi.org/10.1016/j.bios.2014.01.029 